\title{
Nudgital: Critique of Behavioral Political Economy
}

\author{
Julia M. Puaschunder* \\ Columbia University \\ Graduate School of Arts and Sciences \\ $116^{\text {th }}$ Street Broadway, New York, USA
}

\begin{abstract}
*Financial support of the Eugene Lang College of The New School, Fritz Thyssen Foundation, the Janeway Center Fellowship, New School for Social Research, Prize Fellowship, the Science and Technology Global Consortium, the University of Vienna, and Vernon Arts and Sciences is gratefully acknowledged. The author thanks the students of the New School Eugene Lang College Spring 2017 'Behavioral Economics' class for most excellent feedback on the presented ideas and/or earlier versions of this paper. All omissions, errors and misunderstandings in this piece are solely the author's.
\end{abstract}

\section{ABSTRACT}

Behavioral Economics revolutionized mainstream neo-classical economics. A wide range of psychological, economic and sociological laboratory and field experiments proved human beings deviating from rational choices as standard neo-classical profit maximization axioms failed to explain how human actually behave. Human beings rather use heuristics in their day-to-day decision making. These mental short cuts enable to cope with a complex world yet also often leave individuals biased and falling astray to decision making failures. What followed was the powerful extension of these behavioral insights for public administration and public policy making. Behavioral economists proposed to nudge and wink citizens to make better choices for them and the community. Many different applications of rational coordination followed ranging from improved organ donations, health, wealth and time management, to name a few. Yet completely undescribed remains that the implicit hidden persuasion opens a gate to deception and is an unprecedented social class division means. Social media forces are captures as unfolding a class dividing nudgital society, in which the provider of social communication tools can reap surplus value from the information shared of social media users. The social media provider is outlined as capitalist-industrialist, who benefits from the information shared by social media users, or so-called consumer-workers, who share private information in their wish to interact with friends and communicate to public. The social media capitalist-industrialist reaps surplus value from the social media consumer-workers' information sharing, which stems from nudging social media users. For one, social media space can be sold to marketers who can constantly penetrate the consumer-worker in a subliminal way with advertisements. But also nudging occurs as the big data compiled about the social media consumer-worker can be resold to marketers and technocrats to draw inferences about consumer choices, contemporary market trends or individual personality cues used for governance control, such as, for instance, border protection and tax compliance purposes. To draw attention to this implicit struggle within society is important for various reasons: Addressing the nudgital society allows to better understand the laws of motion of governance in the digital age, leading to the potentially unequal accumulation and concentration of power. Technological improvement in the age of information has increased the possibilities to control the innocent social media users and reap the benefits of their existence in hidden persuasion. In the age of populism, nudging can be criticized to be used by the ruling class to exploit the governed populace. In modern democracies, the right to rule was recently plundered in democratic votes through misguiding information of alternative facts and fake news circulated on social media. The socio-ethical crises that are rooted in the contradictory class division of the nudgital society are presented in this paper for the first time and from there on demand for further description and research on 
capitalism and democracy in the digital age. The paper advocates for a democratisation of information, education about nudges and well-informed distribution of transparent governance control.

Keywords: Behavioral Economics, Behavioral Political Economy, Democratisation of information, Education, Exchange value, Governance, Libertarian Paternalism, Nudging, Nudgital, Right to delete, Right to be forgotten, Social media, Social media capitalistindustrialist, Social media consumer-worker, Social media slavery, Surplus Value, Use value, Winking, Winkital.

\section{INTRODUCTION}

Since the end of the 1970ies a wide range of psychological, economic and sociological laboratory and field experiments proved human beings deviating from rational choices and standard neo-classical profit maximization axioms to fail to explain how human actually behave (Kahneman \& Thaler, 1991). Human beings were shown to use heuristics in the dayto-day decision making as mental short cuts that enable to cope with information overload in a complex world (Bazerman \& Tenbrunsel, 2011; Kahneman \& Tversky, 1979; Thaler \& Sunstein, 2008).

From there on, the emerging field of behavioral insights targeted at using human heuristics and biases to improve decision making in different domains ranging from health, wealth and prosperity (Thaler \& Sunstein, 2008). Behavioral economists proposed to nudge and wink citizens to make better choices for them with many different applications. Behavioral Insights teams have been formed to advise individual governments around the globe - for instance, Australia, Canada, Colombia, Germany, Italy, the United Kingdom, and the United States (World Development Report, 2015). But also intergovernmental entities such as the European Commission, or global governance institutions, such as the World Bank and the International Monetary Fund, have started using nudges and winks to improve society (World Development Report, 2015).

While the motivation behind nudging appears as a noble endeavor to foster peoples' lives around the world in very many different applications (Marglin, 1974), the nudging approach raises questions of social hierarchy and class division. The motivating force of the nudgital society may open a gate of exploitation of the populace and - based on privacy infringements stripping them involuntarily from their own decision power in the shadow of legally-permitted libertarian paternalism and under the cloak of the noble goal of welfare-improving global governance. Nudging enables nudgers to plunder the simple uneducated citizen, who is neither aware of the nudging strategies nor able to oversee the tactics used by the nudgers. The nudgers are thereby legally protected by democratically assigned positions they hold or by outsourcing strategies used, in which social media plays a crucial rule.

In the digital age, social media revolutionized human communication around the globe, yet also opened opportunities to unprecedentedly reap benefits from information sharing and big data generation. The law of motion of the nudging societies holds an unequal concentration of power of those who have access to compiled data and who abuse their position under the cloak of hidden persuasion and in the shadow of paternalism. In the nudgital society, information, education and differing social classes determine who the nudgers and who the nudged are. Humans end in different silos or bubbles that differ in who has power and control and who is deceived and being ruled. The owners of the means of governance are able to reap a surplus value in a hidden persuasion, protected by the legal vacuum to curb libertarian paternalism, in the moral shadow of the unnoticeable guidance and under the cloak of the presumption that some know what is more rational than others (Camerer, Issacharoff, Loewenstein, O'Donoghue \& Rabin, 2003). All these features lead to an unprecedented contemporary class struggle 
between the nudgers (those who nudge) and the nudged (those who are nudged), who are divided by the implicit means of governance in the digital scenery. In this light, governing our common welfare through deceptive means and outsourced governance on social media appears critical. In combination with the underlying assumption of the nudgers knowing better what is right, just and fair within society, the digital age and social media tools hold potential unprecedented ethical challenges.

The following article addresses the connection of nudging and social class structure in order to derive conclusions about implicit societal impetus of nudging and winking in the $21^{\text {st }}$ century. Alongside of providing an overview of behavioral sciences with an application in the public domain; the following paper will take a critical approach in the economic analysis of contemporary public governance through nudging and winking enabled through social media. Drawing from some of the historical foundations of political economy, the paper seeks to advance the field of behavioral economics through a critical stance on behavioral sciences and new media use for guiding on public concerns in the digital age (Heilbroner, 1988, 1999).

In its totality, the article offers a critical analysis of behavioral economics with an emphasis on political economy. By revealing the contradictions of the social media age of the nudgital society, light is shed on the implicit class struggle rooted in the nudgital social relations of production. Pointing out the limitations of behavioral insights to inform about public choices accurately will be the basis of the critique of a certain ruling class nudging a wide populace by the help of social media. An analysis of the process of the circulation of information leads to conclusions about the metamorphosis of big data and their circuit. By shedding light on the inherent class division in those who nudge (the nudgers) and those who are being nudged (the nudged), the article proposes further analysis strategies to unravel how the use of behavioral economics for the greater societal good in combination with the rise of social media big data creation may hold unknown socio-ethical downfalls. The paper thereby takes a heterodox economics stance in order to search for interdisciplinary improvement recommendations how to more inclusively alleviate public sector concerns in the digital age.

The article is structured as follows: An introduction to behavioral economics nudging is followed by a description of social hierarchy in the nudgital society. The underlying structures that lead to a class division in those who nudge and those who are being nudged are captured for the first time in order to draw conclusions about the hidden downfalls and risks of the nudgital society. Implications of invisible governance through nudging lead to open questions about ethics in the information age and recommendations for societal and democratic improvement in the $21^{\text {st }}$ century. The paper closes with a preview of potential future directions of the novel insights gained on the nudgital society. Challenging contemporary behavioral insights theory is aimed at moving together towards a more inclusive future wiser, more self-informed and protected digital society.

\section{BEHAVIORAL ECONOMICS}

Behavioral Economics revolutionized decision-making theory. By studying human decision making fallibility and its consequences, behavioral economics argues that people make decisions based on rules of thumb heuristics that dominate human choices (Gigerenzer, 2014, 2016; Kahneman \& Tversky, 2000). Laboratory experiments have captured heuristics as mental short-cuts easing mentally constrained human in a complex world (Cartwright, 2011; Sen, 1977; Simon \& Bartel, 1986). Mental short cuts were outlined to simplify decision making and substitute difficult questions with easy applicable automatic behavioral reactions (Kahneman, 2003). An impressive line of research has shown that heuristics lead to 
predictable and systematic errors (Tversky \& Kahneman, 1974). Heuristics cause people to make choices much faster, but ultimately less logically than more careful, long-form, decision making. These cognitive mental shortcuts therefore set humans on a path to erroneous choices. From these insights gained, decision making failures became studied in order to improve human decision making outcomes over time and in groups (Camerer \& Loewenstein, 2004).

Behavioral economists have recently started to nudge - and most recently wink - people into favorable decision outcomes, offering promising avenues to steer social responsibility in public affairs (Akerlof, 2009; Kahneman, 2011). Individuals were nudged into doing things they naturally would not have considered doing. Most recently, behavioral economics innovatively became applied in the public administration and policy domain as a cutting-edge approach to capture the power of real-world relevant economics for the improvement of society. Drawing from a line of research on bounded rationality, behavioral economics accounts for one of the most prominent approaches to minimize societal downfalls and implement social welfare maximization. Behavioral economics is thereby seen as a real-world relevant means to enable global governance in the world economy and improve societal advancement on a global scale (World Development Report, 2015). Yet questionable is whether or not economic calculus can be applied onto the governance of human activity within society without ethical oversight (Puaschunder, 2010). Heuristics may be studied to help explain why people may act illogical and how their fast and impulsive decision making can be turned against them. As a novel application of political economy, the behavioral insights approach appears to be limited and hold unforeseen risks of social class division in the digital age (Bowles, Edwards \& Roosevelt, 2005; Sidanius \& Pratto, 1999; Tajfel \& Turner, 1979).

\section{THE NUDGITAL SOCIETY}

In order to understand the impetus of the nudgital society, we need to study the laws of governance in the age of information. From primitive communication between human beings, a civilization of information transfer with centralized state authority and market value in communication control has emerged. In the $21^{\text {st }}$ century, the turnover of information and the aggregation of social informational capital has revolutionized the world. In the wake of the emergence of new social media communication and interaction methods, a facilitation of the extraction of surplus value in shared information has begun. In the following the main ideas behind the social media marketplace are dissected in order to show how surplus value through access to amalgamated information over distance and time is realized and an implicit social class division between the nudgers and the nudged evolved in the digital age.

Imagine signing up for a free social media tool, such as Facebook, Instagram or Twitter. You will connect with other people and constantly upload information about yourself, your life and your friends in order to share and benefit from shared information. New media online communication tools have made the world flat. No social hierarchies exist when considering one can follow powerful peoples' news on Twitter and the opportunity to connect and feedback influential individuals' web-appearances. No distance in space and time seem to matter in the light of our all opportunities to instant messaging around the globe 24/7, send messages post-humously and compile massive amounts of big data on a constant basis, which can be stored eternally. All these information flows can be combined to find fascinating behavioral insights and learn about market trends thanks to unprecedented computational power in the $21^{\text {st }}$ century. Computational procedures for data collection, storage and access in the large-scale data processing has been refined for real-time and historical data analysis, spatial and temporal results as well as forecasting and nowcasting throughout recent decades. All these advancements have offered a multitude of in-depth information on human biases and imperfections as well as social representations and collective economic trends (Minsky, 1977; 
Moscovici, 1988; Wagner \& Hayes, 2005; Wagner, Lorenzi-Cioldi, Mankova \& Rose, 1999; Puaschunder, 2015). But are these features of the digital age solely positive advancements of humankind or do they hold problematic emergent risks for humanity and implicit danger of societal stratification (Centeno, Nag, Patterson, Shaver \& Windawi, 2015)? Are the behavioral insights gravitating towards an elite that holds the power to reap benefits from the many who innocently share personal information by giving in to the humane-imbued need for expression and interpersonal communication? Do the novel computational power advantages lead to a divided society and an unequal distribution of political power and unequal means to steer collective action (deRooij, Green \& Gerber, 2009)?

The article examines the relationship between heuristics, nudging and social class in the digital age. Thereby the paper argues that the strategic use of heuristics differs across social classes. Nudging becomes a prerogative of the elite, who has more information given a difference in access to compiled information. In the nudgital society, information about others plays a key role in determining a competitive advantage. The digital age has brought about unprecedented opportunities to amalgamate big data information that can directly be used to derive inferences about people's preferences in order to nudge and wink them in the nudgitalist's favor. Social classes have different levels of education and insights about the nudgital act, which lead to different confidence levels in their economic choices to act on the nudgital insights and to abstain from opt-out devices. Those who reap surplus value are naturally blessed with higher income levels and elevated educational backgrounds coupled with selfconfidence, which leads to less susceptibility to fall for nudges and winks. These elite circles are more confident in their decision making and respond more well-informed to opt-out options.

In today's nudgital society, information has become a source of competitive advantage. Technological advancement and the social media revolution have increased the production of surplus value through access to combined information. Human decisions to voluntarily share information with others in the search for the humane pleasure derived from communication is objectified in human economic relations. Unprecedented data storage possibilities and computational power in the digital age, have leveraged information sharing and personal data into an exclusive asset that divides society in those who have behavioral insights derived from a large amount of data (the nudgers) and those whose will is manipulated (the nudged).

The implicit institutional configuration of a hidden hierarchy of the nudgital society is structured as follows: Different actors engage in concerted action in the social media marketplace. The nudgital-brokers are owners and buyers of social media space, which becomes the implicit means of the production. In the age of instant global information transfer, the so-called social media industrialist-capitalist provides the social media platform, on which the social media consumer-workers get to share information about their life and express their opinion online for free. In their zest for a creation of a digital identity on social media platforms, a 'commodification of the self' occurs (Pincus in speech, March 30). Social media consumer-producer-worker are sharing information and expressing themselves, which contributes to the creation of social media experience.

The hidden power in the nudgitalist society is distributed unevenly, whereby the social media consumer-workers are slaves, who receive no wages in return for their labor, falling for their own human nature to express themselves and communicate with one-another. Social media consumer-workers also engage in social media expression as for their social status striving in the social media platforms, where they can promote themselves. By posing to others in search 
for social status enhancement and likes, they engage in voluntary obedience to the social media capitalist-industrialist who sells their labor power product of aggregated information to either capitalists or technocrats. The social media consumer-worker's use value is inherent in their intrinsic motivation to satisfy a human need or want to communicate and gain respect from their community. The use value of the commodity is a social use value, which has a generally accepted use-value derived from others' attention and respect in the wake of information sharing in society. The social media provider gives the use value an outlet or frame, which allows the social media consumer-worker to express information, compare oneself to others and gain information about the social relation to others. The consumer-laborer thereby becomes the producer of information, releasing it to the wider audience and the social media industrialist. This use value only becomes a reality by the use or consumption of the social media and constitute the substance of consumption. The tool becomes an encyclopedic knowledge and joy source derived from the commodity.

But the use of social media is not an end in itself but a means for gathering more information that can then be amalgamated by the social media capitalist-industrialist, who harvests its use value to aid nudgers (Marx, 1867/1995). It is a social form of wealth, in form of social status and access to knowledge about others that the use value materializes on the side of the industrialist in the exchange value. For the social media industrialist, who is engaged in economic and governmental relations, the exchange value of the information provided by his or her social media consumer-laborers is the information released and consumption patterns studied. In exchange this allows to derive knowledge about purchasing and consumption patterns of the populace and therefore creates opportunities to better nudge consumers and control the populace. With the amalgamated information the social media industrialistcapitalist can gain information about common trends that can aid governmental officials and technocrats in ensuring security and governance purposes. Further, the social media platform can be used for marketing and governmental information disclaimers.

Exchange value is a social process of self-interested economic actors taking advantage of information sharing based on utility derived from consuming the social media. The social media industrialist-capitalist can negotiate a price based on the access to the social media consumer-worker's attention and sell promotion space to marketers. The exchange value of the commodity of information share also derives from the subjective perception of the value of amalgamated data. Exchanged information can be amalgamated by the social media industrialist-capitalist and traded to other market actors. Exchange value is derived from integrating everything the worker is and does, so both in his creative potential and how he or she relates to others. Exchange value also stems from the exchange of the commodity of amalgamated information that enables an elite to nudge the general populace. The amalgam of information as a premium signals the average opinion and how the majority reacts to changing environments, which allows inferences about current trends and predictions how to react to market changes.

Underlying motives may be the humane desire for prestige and distinction on both sides - the industrialist-capitalist's and the consumer-worker's. From the industrialist-capitalist's perspective, monetary motives may play a role in the materialization of information; on the consumer-worker's side it is the prestige gained from likes, hence respect for an online identity created. The benefits of the superior class are the power to nudge, grounded on the people's striving for prestige and image boosts. Emotions may play a vital role in seducing people to share information about themselves and derive pleasure for sharing (Evans \& Krueger, 2009; Horberg, Oveis \& Keltner, 2011; Lerner, Small \& Loewenstein, 2004). Social norms and herding behavior may be additional information sharing drivers (Paluck, 2009). The 
realization of prestige stems from creating a favorable image of oneself online, which signs up the workers in a psychological quasi-contract to provide more and more information online and in a self-expanding value. Prestige is also gained in the materialization of information as asset by the capitalist-industrialist, who reaps the surplus value of the commodification of the self of the consumer-worker (Marx, 1867/1995). The social media capitalist-industrialist therefore increases their capital based on the social media consumer-worker's innocent private information share. The social media capitalist-industrialist also accumulated nudgital, the power to nudge.

This information sharing opens a gate for the social media provider to reap surplus value from the information gathered on social platforms and to nudge the social media consumerproducers or resell their amalgamated information to nudgers. Crucial to the idea of exploitation is the wealth or power of information in the digital age. Surplus of information can be used to nudge in markets and by the force of governments. To acknowledge social media consumers as producers lead to the conclusion of them being underpaid workers in a direct wage labor exploitation. Surplus gravitates towards the social media owning class. Information becomes a commodity and commodification a social product by the nature of communication. Commodification of information occurs through the trade of information about the consumer-worker and by gaining access to nudge consumer-workers on social platforms. The transformation of a labor-product into a commodity occurs if information is used for marketing or governance purposes to nudge people. In the contemporary big data society, the nudged social media user therefore end up in a situation where they are unwaged laborers, providing the content of entertainment within social media, whereas the social media industrialist-capitalist, who only offers the information brokerage platform, reaps benefits from the amalgamated information shared. Not just labor power but the whole person becomes the exchange value, so one could even define the consumer-worker as utility-slave.

The technological complexity of digital media indicates how interrelated social, use and exchange value creation are. All commodities are social products of labor, created and exchanged by a community, with each commodity producer contributing his or her time to the societal division of labor. Use value is derived by the consumer-worker being socially related insofar as private consumption becomes collective. The use value thereby becomes the object of satisfaction of the human need for social care and want for social interaction. The use value becomes modified by the modern relations of production in the social media space as the consumer-worker intervenes to modify information. What the consumer-worker says on social media, for the sake of communication and expression but also in search for social feedback, is confined by the social media industrialist-capitalist, who transforms the use value into exchange value by materializing the voluntary information share by summing it up and presenting it to nudgers, who then derive from the information marketability and nudgitability of the consumer-workers. All information sharing has value, or labor value, the abstract labor time needed to produce it. The commodification of a good and service often involves a considerable practical accomplishment in trade. Exchange value manifests itself totally independent of use value. Exchange means the quantification of data, hence putting it into monetary units. In absolute terms, exchange value can be measured in the monetary prices social media industrialist-capitalists gain from selling advertisement space to nudging marketers but also to public and private actors who want to learn about consumer behavior in the digital market arena and influence consumers and the populace. The exchange value can also be quantified in the average consumption-labor hours of the consumers-workers. While in the practical sense, prices are usually referred to in labor hours, as units of account, there 
are hidden costs and risks that have to factored into the equation, such as, for instance, missing governmental oversight and taxing of exchange value.

Overall, there is a decisive social role difference between the new media capitalist-industrialist and the social media consumer-worker. The social media provider is an industrialist and social connection owner, who lends out a tool for people to connect and engage with. As the innovative entrepreneur who offers a new media tool, the industrialist also becomes the wholesale merchant in selling market space to advertisement and trading information of his customers or workers, who are actively and voluntarily engaging in media tools (Schumpeter, 1949). The social media consumers turn into workers, or even slaves if considering the missing direct monetary remuneration for their information share and since being engaged in the new media tool rather than selling their labor power for money in the market place holds opportunity costs of foregone labor. While selling their commodity labor power, the social media consumer-workers are also consumers of the new media tool laden information, which can be infiltrated with advertisement. The social media capitalist-industrialist not only reaps exchange value benefits through access to people's attention through selling advertisement space, but also grants means to nudge the consumers into purchasing acts or wink the populace for governance authorities (Marx, 1867/1995). The social media capitalistindustrialist thereby engages in conversion of surplus value through information sharing into profit as well as selling attention space access and private data of the consumer-workers.

When the new media consumer-workers' amalgam of provided information gets added up to big data sets, it can be used by capitalists and governance specialists. Over time the nudgital society emerges, as the nudging social media industrialist-capitalists form a Gestalt of several bits and pieces put together about the nudged social media consumer-producer-worker-slaves. Information gets systematically added up providing invaluable behavioral insights. Information in its raw form and in amalgamated consistency then gets channeled from the broad working body on social media into the hands of a restricted group or societal class. This circulation of information and the distribution into those who provide a medium of information exchange and those who exchange information that then forms a society in those who nudge and those who are nudged implying an inherent social class divide.

In the nature of exchange, nudgital becomes an abstract social power, a property claim to surplus value through information. Value can be expropriated through the exchange of information between the industrialist-capitalist and the nudgitalist. Exchange value has an inherent nature of implicit class division. Exchange value represents the nudgitalists' purchasing power expressed in his ability to gain labor time that is required for information sharing as a result of the labor done to produce it and the ability to engage in privacy infringements. The social media industrialist-capitalists implicitly commands labor to produce more of data through social nudging and tapping into humane needs to communicate and express themselves, whereby he or her use a reacting army of labor encouraging information share through social gratification in the form of likes and emoticons. The reacting army of labor is comprised of social media users, who degrade into hidden laborers that are not directly compensated for their information share and cheerleading others to do the same. The nudgital society's paradox is that information sharing in the social compound gets pitted against privacy protecting alienation.

The social relations of production in the social media domain and existing within economic exchange of big data are yet rather uncaptured. The social concept of information value therefore need to be highlighted in order to derive conclusions about the labor theory of social media exchange value. While social media appears to create a flat and more egalitarian society, 
and social hierarchies have indeed become flat in the availability to connect with different social strata around the world on an instant basis, a domination occurs in human society through the nudgers, who gain access to private information of social media users. Their amalgamation of data individuals' private information allows to predict trends but also to manipulate the consumers and populace. While for the consumer-worker information sharing seems no concern since it is with his/her preferred circles, the industrialist-capitalist gains an elevated position through the exchange value, leveraging him into a quasi-bourgeois class thanks to the voluntary, innocent information share of his or her workers.

Nudgers and nudged form different social classes. The nudgers are those who augmented a higher than average amount of information value in society, while simultaneously diminishing the privacy and economic value creation of the nudged. Decision making biases and heuristics come to play to create illusions in order to maximize economic value. The implicit governance system of the nudgital society continues to operate behind the backs of the nudgers and the nudged as the nudgers gain big data information over time and different media spaces.

The insights gained about the nudgital society, lead to the demand to rewrite economics. Standard neo-classical economic theories do not hold, when it comes to the nudgital society. In constant striving to increase his or her power, the social media capitalist-industrialist constantly seeks to accumulate power in the form of information about others in order to use this information to reap exchange value through selling the amalgam of the information to create nudges for capitalists and technocrats. Since the social media industrialist has no direct contract with social media consumer-producers, he or she cannot coerce or enforce work discipline rather than having to entertain the workforce. Social media capitalist-industrialists therefore constantly have a need to find novel ways to entertain their online entourage workforce to stay online in order to better amass information. The marginal utility of consumption rate is - contrary to neoclassical economic theory - increasing as the more time one spends on social media, the more pleasure is derivable as for making more connections and having a more complex network with more access to information of a wider variety of people. Contrary to the falling rate of profit concept prevailing in economic models (Shaikh, 2016), the rate of profit for the nudgital society therefore increases over time and with claiming nudging space. The rate of profit is rising with the more people being engaged in the network and the capitalist-industrialist's successful efforts to restlessly and insatiable accumulate information. The more people join a network, the more time they may spend on the social media tool and the more likely they are assumed to release information and voluntarily share information. There is no falling rate of profit as information value gains rise exponentially when considering the Gestalt the capitalist-industrialist can form. So contrary to classical economic market models, the rate of profit for the new media industrialist-capitalist is assumed to be rising with the more people engaging in his or her market tool. Yet there is a tendency of the rate of profit to fall if other social media contestants invent other social media tools that distract workers from their task of sharing information. The industrialist-capitalist is thereby in a constant battle with other social media providers for attention of customerworkers. Since the customer-workers are non-financially rewarded, their attention has to be drawn by the industrialist-capitalist, who only technically intervenes, not actively contributes information. The capitalist-industrialist is under constant pressure of the market needing to track the wants and needs of consumers and keeping them motivated to engage on social media and share information in order to collect information of individuals throughout all social strata of society. This process may not only be influenced by economic and technical factors but also socio-political and cultural ones, insofar as it involves property rights, claims to private resources and consumes time while being at risk to infringe upon quality and safety of 
use. In addition, negative market forces are fake news and alternative facts. Alternative facts can curb people's motivation to engage in social media and spend time on certain social networks.

The falling rate of profit in the nudgital world could also be falling if people start getting bored by social media and not upload information as they used to. This leads to a constant struggle for new social media tools and entertainment features where to derive novel utility or expanded utility from. Novel and newly designed systematic encouragements (e.g., the like button) and the development of technological capabilities of all kinds become an integral consequence for the circuit of information accumulation. The constant need to create surplus value and to protect oneself against forces that erode information sharing is alleviated by technological innovations. When innovation takes the form of a new product, the capitalist enjoy a monopolistic profit advantage, which yet may often be short-lived. Novel surplus may derive from activities on social media that bring unique novel pleasure or use values that yield a profit to their organizers in the institutional structure of the system and its technical apparatus. The state of the market determines the social media capitalist-industrialist's impetus. The social media capitalist-industrialist's productive activity is an ongoing process determined by attention people give to social market tools. The market reality is the conservation, transfer and addition of Gestalt of market data released from social media consumers' living labor and the subsequent sales of outputs for money units. The information release and sales of information is the socially determining factor in the nudgital economy. Price fluctuations may occur through differences in information collected.

The imposition of exclusivity of access to information holds social implications. The possibility of the industrialist-capitalist to use the information and the ability to produce a situation on social media that attracts consumer-workers at a cost to yield an adequate and predictable income or reap their foregone profit holds an implicit social stratification. The hidden possessor's elevated position in the amalgamation of information drives a class division and distinction of authority, which becomes visible in understanding the nudgitalist's actions. The capitalist social formation includes that the dominant class renews its social control through transforming information into money. Thereby the end goal of the capitalist-industrialist is to gain as much of the public's information in light of the end goal of accumulation of wealth. In reinventing newly designed information sharing tools and options, there is a systematic encouragement and development of technological capabilities of all kinds to share information and keep the information flow alive. Pleasure of the use value of information sharing yields to an inferior position as capital expands for the information shared and privacy gets infringed upon and people are being nudged. With the information gathered, consumer profiles can be obtained that help to nudge people into making decisions, may that be purchasing or voting choices. There is also the authority to gather information that may be used against civilians when entering nations at borders or in extending visas or when checking on their tax honesty. The domination of the nudgital society then lies insofar as there is a right to deny others access based on the interpretation of data that can be used to control the populace and may also be turned against them in democratic votes.

The augmentation of information leads to the manifestation of power of a dominant class of nudgers, who only entertain their workers for the final purpose to generate information that then gets transferred to use value in nudging into purchasing decision and civilian order. Social media is therefore a process that uses online tools to constitute different social classes in their dynamic existence. The owners of social media power are the momentary embodiment of the nudgital society, whereas the users of social media tools are carrying on their activity of production of nudgital information surplus value. Their property of information and privacy 
gets shared, which allows the amalgamation of information and possession of user profiles and customer and civilian tendencies of the social media capitalist-industrialist, who can then materialize the surplus value gained. Exploitation occurs in the private information materialization of the social media capitalist-industrialist. The social media consumerworker's individual privacy is not respected as the relation between the nudger social media capitalist-industrialist and the nudged is one by hidden domination and exploitation, in which one party holds an amalgam of information about the other that is also gathered implicitly. The social media consumer-worker loses their right to privacy and has no access to the whole product of their labor. Certain economic hierarchies in the digital age thus form certain unfair social strata. An alienation of all classes of society emerges as a consequence, in which communication and information sharing holds novel unprecedented risks. Private property of private information gets turned into a collective big data that is only accessible by a refined group of people - a state that leads to an implicit social class division. The social media consumer-worker becomes poorer the more information is shared and the more wealth he or she produces for the social media capitalist-industrialist. The increasing value of information amalgamated proceeds in direct proportion with the loss of privacy property and the devaluation of human dignity. The laborer no longer owns his or her privacy as he or she enriches others with their products of labor, who benefit from their work. The labor force is thereby alienated through the underlying social division arising in the contrast between nudging and being nudged. The natural relations created by this implicit structure is the power that lies in the nudgital society. The nudgital society thereby implies a trade-off between privacy and pleasure derived from information sharing. Revealing the technicalities of the nudgital society and the implicit relation of domination and slavery naturally leads to an alienation of workers and the demand for protecting their right to privacy and protected free speech.

\section{IMPLICATIONS OF THE NUDGITAL SOCIETY}

The wider impetus of this article is to build a scientific foundation for the politics of modern social media use and reveal the law of motion of the modern nudgital society. The nudgital hierarchy unfolds based on the social media mode of production. The use value is thereby the utility derived from sharing and receiving information; the exchange value the social media industrialist-capitalist gains from access to information that can be computed into big data that allows deriving behavioral insights for markets and governance technocrats. The use value is thereby the utility of consuming social media, the want-satisfying power of a good in the classical political economy sense. The information released by the consuming workers becomes an exchange value in big data sold to marketers and technocrats to gain information about nudgebility of potential consumers and general populace (Kurz, 2016). The exchange value is retrieved from simple information circulation and the circulation of value as nudgital, the power to nudge.

The machinery of the social media industrialist-capitalist is the social media users' production as a self-acting automata and the consumer-worker gaining gratification through likes and delving into a phantasy world of the self. Information amalgamation can become an act of critical social consequence, which is capital-oriented towards making use of use value in the form of exchange value in the materialization of information. The nudgitalist exploitation begins when information gets turned against individuals. A Gestalt through the bits and pieces of the individually shared information creates an unfavorable condition in terms of consumer exploitation and in front of governmental authorities. People end up in a subordinate position of their information being turned against them within the digital society. Not only does the social media consumer-workers' dependence on communication media infringes on their 
privacy. Their social relations get exposed and they lose their privacy to those owners of the means of social media production. Information can also be used to nudge people into making choices, may that be consumer decision or may that be their political choices.

The nudgitalist exploitation also holds when technocrats use heuristics and nudges to create selfish outcomes or undermine democracy. Ethical abysses of the nudgital society open when the social media is used for public opinion building and public discourse restructuring. Social media not only allows to estimate target audience's preferences and societal trends but also imposes direct and indirect influence onto society by shaping the public opinion with real and alternative facts. Government officials' gaining information about the populace that can be used to interfere in the democratic voting process, for instance in regards to curbing voting behavior or misinformation leading people astray from their own will and wishes. The social intertwining of the media platform and the democratic act of voting has been outlined in recent votes that were accused to have been compromised by availability heuristic biases and fake news. Data can also be turned against the social media consumer-worker by governance technocrats for the sake of security and protection purposes, for instance, social media information can be linked together tax verification purposes.

Governments have been transformed under the impact of the digital revolution. Instant information flow, computational power and visualization techniques, sophisticated computer technologies and unprecedented analytical tools allow policy makers to interact with citizens more efficiently and make well-informed decisions based on personal data. New media technologies equip individuals with constant information flows about informal networks and personal data. Novel outreach channels have created innovative ways to participate in public decision making processes with a partially unknown societal impact at a larger scale, scope and faster pace than ever before. Big data analytics and the internet of things automate many public outreach activities and services in the $21^{\text {st }}$ century. Not only do we benefit from the greatly increasing efficiency of information transfer, but there may also be potential costs and risks of ubiquitous surveillance and implicit persuasion means that may threaten democracy. The digital era governance and democracy features data-driven security in central and local governments through algorithmic surveillance. Open source data movements can become a governance regulation tool. In the sharing economy public opinion and participation in the democratic process has become dependent on data literacy. Research on the nudgital society holds key necessary information about capacity-building and knowledge sharing within government with respect for certain inalienable rights of privacy protection. The nudgital society's paradox that information sharing in the social compound gets pitted against privacy protecting alienation requires an ideological superstructure to sustain and tolerate hidden exploitation.

All these features are modern times phenomena as the technology and big data creating computational power is currently emerging. The transferability of the commodity of information itself, hence the big data amalgamation over time and space to store, package, preserve and transport information from one owner to another appears critical. The legal leeway to allow private information sharing implicitly leads to individuals losing their private ownership rights to the commodity of information upon release on social media and the right to trade information. The transferability of these private rights from one owner to another may infringe on privacy protection, human rights and humane dignity upholding mandates.

Not only pointing at the ethical downfalls of the nudgital society, also defining social media users as workers is of monumental significance to understand the construction of the nudgital society and bestow upon us social media consumer-workers labor rights. The technical 
relationship between the different economic actors are completely voluntary and based on trust (Puaschunder, 2016a, b). The creation of use value is outsourced to the community (e.g., in likes) and the share of information about the workers from the social media capitalist to the market or nudgitalists remains without a clear work contract and without protection of a labor union. The worker-employer relationship needs to be protected and a minimum wage should settle for the market value of the worker producing during the working day. Wages would be needed to maintain their labor power of the workers minus the costs of the production. Unpaid laborers should not only be compensated for their opportunity costs of time but should enjoy the workers' privilege of right to privacy, prevention of misuse of the information they share and have the right to access to accurate information but also protection from nudging in the establishment of the right to voluntary fail.

The nature of making profit from information in exchange value is questionable. Information exchange of the industrialist-capitalist is different than neoclassical goods and services trade insofar since for the capitalist-industrialist making money off privacy and the consumerworkers share of information without knowledge and/or control over the recipient of the amalgamated mass of privacy released. Workers are never indifferent to their use value and their inputs may also produce unfavorable outcomes for them. The exchange value will sell for an adequate profit and is legally permitted, yet it can destroy the reputation and standing as well as potentially the access of the individual to country entrance if considering the proposed social media information release mandate at border controls. Care must be taken for privacy infringement and the product of amalgamated big data and how useful it is for society.

By shedding light on these risks of the social media age and the implicit dynamism of capitalism forming around information, a social formation of social media workers' right can be heralded. Social media user-workers should be defined to hold inalienable rights to privacy and be forgotten (part 4.1), to be protected from data misuse of information they share (part 4.2 ), they should be granted the right to access of accurate information (part 4.3) and - in light of the nudgitalist audacity - the right to fail (part 4.4).

\section{People's right to privacy and to be forgotten}

The transformation of a use value into a social use value and into a commodity has technical, social and political preconditions. Information gets traded and ownership of privacy transferred in information sharing. Upon sharing information on social media, the consumerworker bestows the social media capitalist-industrialist with access to previously private information. The social media capitalists then transforms the information into use value by offering and selling the bundled information to nudgitalists, who then can draw inferences about certain consumer group's preferences and guide their choices.

Overall, the nudgital society leads to a dangerous infringement upon the independence of individuals in their freedom of choice and a social stratification into those who have access to the amalgamated information of social media consumer-workers. There is a trade-off between communication and privacy in an implicit contract of the use of personal data. Power is exercised through the accumulation of information, including the quality of insatiability of social media consumer-workers to constantly upload information and the social media capitalist-industrialist reaping profits from selling it.

Social media thereby reveals to hold a sticky memory that allows storage of information in the international arena eternally. Privacy and information share regulations depend on national governments. For instance, in the commodification of privacy, the EU is much more beneficial 
to consumers than that of the US. Data protection and commercial privacy are considered as fundamental human rights to be safeguarded in Europe. In contrast, the US approach towards commercial privacy focuses on only protection the economic interests of consumers. Current privacy regulations are considered as not sufficient in targeting actions that cause noneconomic and other kinds of harm to consumers.

Privacy and information sharing guidelines appear to be culturally-dependent phenomena. Information about privacy boundary conditions can be obtained from the transatlantic dialog between the US and Europe on privacy protection. While in Europe health care data is public, in Canada, there is a public interest to make the data more public. The EU's privacy approach is based on Article 7 and 8 of the Charter of the Fundamental Rights of the EU, which grants individuals rights to protection, access and request of data concerning him or herself. European privacy is oriented around consumer consent. The 2016 EU General Data Protection Regulation (GDPR) ruled the right to be forgotten under certain circumstances. Consumer consent and dealing with incomplete, outdated and irrelevant information is legally regulated. GDPR establishes regulatory fines for non-complying companies applicable to foreign companies whose data processing actions are related to 'good and services' that they provide to data subjects in the EU, so also including US companies operating in the virtual space accessible by European citizens. The EU privacy approach offers member states flexibility in data management for national security and other exceptional circumstances but also protects civilians from common potential circumstances for data abuse; while there are standardized data management policy procedures regardless of a companies' country-of-origin or operational locations. The EU's privacy approach has higher regulatory costs, is not specified by sectors and the right to be forgotten still needs enforcement validity.

The US approach to privacy is sector specific. Commercial privacy is pitted against economic interests and neither seen as civil liberty nor as constitutional right. US privacy is regulated by the Federal Communications Commission (FCC) and the Federal Trade Commission (FTC). Overall in the US, the general definitions of unfair and deceptive give the FTC a wider scope for monitoring and restricting corporate privacy infringements. The FTC has a wide variety of tools for data protection, yet the responsibility is split between the FTC and the FCC, which increases bureaucratic and regulatory costs and limits industry oversight.

So while the EU framework treats commercial privacy as a basic human right leading to a more extensive protection of individual's privacy including data collection, use and share, the EU framework is also non-sectoral and allows sovereign nation states to overrule common data management policies for the sake of national security and protection. The US framework lacks a centralized privacy regulation approach, yet is sector but split regarding oversight in the domains of the FCC and FTC.

\section{People's right to prevent misuse of information they share}

By US standards, social media is required by the FTC to ask users for permission if it wants to alter its privacy practices. Under Section 5 of the FTC Act that states that (1) unfair practices are causes or is likely to cause substantial injury to consumers or cannot reasonably be avoided by consumers; and (2) deceptive practices are practices that likely are misleading or actually misleading the consumer.

In August 2016 decision of WhatsApp to sharing more user data, especially user phone numbers - with Facebook in order to track customer-workers' use metrics and targeted user advertising. This decision faced a huge backlash in the EU, where data sharing was ordered to be halted and Germany deemed its practices as illegal. In the US the Federal Trade Commission 
(FTC) began reviewing joint complaints from consumer privacy groups. The recent WhatsApp data sharing is a possible violation of this requirement since it only allowed consumers to opt out of most of the data sharing while lacking clarity and specificity. WhatsApp's restrictive opt out option and incomplete data sharing restrictions were argued to be perceived as unfair and deceptive (Tse, in speech, March 25).

\section{People's right to access to accurate information}

In the nudgital society, profits appear in the circuit of information and take on different forms in the new media age. The possibility of trading information and reaping benefits from information sharing of others determines the unequal position of people in society. The possession of knowledge stems from the surplus derived from the activity of production, hence the information share of social media consumer-producers. This confrontation of labor and consumption is not apparent in the modern marketplace. The class division remains quite invisible in the implicit workings of the system.

The nudgitalist act becomes problematic when being coupled with infiltration with fake news and alternative facts that curb democratic acts, e.g. manipulating voting behavior. Ethical questions arise if it there is a transparency about the capitalist's share of information and a fair social value benefits distribution among the capitalist and the worker. In addition, under the cloak of security and protection, privacy infringements by sharing information with the nudgitalist is questionable. By outlining these market procedures, fairness in the distribution of gains should be accomplished and privacy infringing information sharing limited or at least guided by the legal oversight. Access to information about the storage, preservation, packaging and transportation of data is non-existent, demanding for more information about behind-thescenes' social media conduct. Transforming private information from use value to exchange value is an undisclosed and therefore potentially problem-fraught process that holds implicit inequality within itself. From a societal standpoint, also the missing wealth production in the social media economy appears striking. Thereby the dangers of information release and transfer and the hidden exchange value accrued on the side of the media innovator is left unspoken. The importance of shedding light on such, though, is blatant as for stripping the populace from inalienable rights of privacy while reaping benefits at the expense of their susceptibility. Nudges in combination with misinformation and power abuse in the shadow of subliminal manipulation can strip the populace from democratic rights to choose and voluntary fail.

\section{People's right to choose and fail}

In the personal information sharing age and nudgital society, attention must be given to privacy and human dignity. The nudgital society opens a gate to gain information about consumer choices and voting preferences. The uneven distribution of key information about people's choices opens a gate to tricking people into choices. The so-called nudging attempt though raises ethical questions about human dignity and the audacity of some to know better what is better for society as a whole. Because governance is a historical process, no one person can control or direct it, thereby creating a global complex of governance connections that precedes the individual administration. Structural contradictions describe the class struggle between the nudged in opposition to the nudgers in the nudgital society. Since societal actors who involuntarily are nudged are separated from an active reflection process when being nudged, the moral weight is placed on the nudger. Though democratically elected and put into charge, the nudgers checks-and-balances of power seem concentrated and under disguise through the middle man of social media capitalist-industrialists who collect information. 
Rather focusing on how to trick people into involuntary choices, the revelations should guide us to demand to educate people on a broad scale about their fallibility in choice behavior.

In a self-enlightened society, people have a right to voluntary fail. Nudging implies a loss of degrees of freedom and disrespect of human dignity, hence the nudgital society will lead to structural contradictions. Their rational thinking and voluntary engagement in governmentally-enforced action becomes divorced from rational reflection. No one entity should decide to control or direct other's choices, thereby creating a global complex of social connections among the governed for the sake of efficiency for the common good. The economic formation of human decision making in society should never precede the human voluntary decision.

There is an inherent inequality of social positions, manifested primarily in the respective capacities of reaping benefit from amalgamated information, which leads to a disparity of social position. The distribution of power leads to a natural order of human activity, in which the nudgers are in charge of nudging the populace. Moral value is separated from economic value and hence placing the fate of the populace into the arms of the behavioral economists raises problems of lack of oversight and concentration of objective economic value rule in the nudgital society.

Overall, with the communication on the nudgital society just having started, it remains on us to redesign the apparatus of production in ways that make impossible the infringement on private information through the natural tendency to share information, care about others and express oneself. Governance crises are rooted in the contradictory character of the value creation through big data. The formation of value is a complex determination and we still need more research to understand the deep structures of market behavior in the digital age.

\section{DISCUSSION AND FUTURE PROSPECTS}

The article presented a novel idea in connecting behavioral economics with political economy. Behavioral insights are critiqued insofar as the contemporary behavioral economics approach and extension of behavioral economics application to public sector problems are shown to hold an implicit underlying social stratification. Democratically empowered nudgers decide without democratic consent whom to nudge, how to nudge and what for to nudge. The potential impact of the paper for public concerns is to raise a democratic feasibility check of nudging being in line with constitutional values and informed consent demands. In this challenge of the mainstream behavioral economics also lies a direct contribution to scientific knowledge spearheading social dominance theory. The marketability of results demands for oversight of the nudgers and well-informed decision making in an inclusive society. Future research directions and policy recommendations are given that aim at informing scientific audience, helping public policy specialists and empowering the general populace about behavioral economics and their right to choose and fail. Challenging concerns about libertarian paternalism lead to the quest for people having the right to fail. In sum, the current article serves as preliminary first introduction of a behavioral economics critique and application of political economy and social dominance theory in the behavioral insights domain for the sake of protection of people's right to fail. The aim is to provide insightful information on how society can make rational decisions in order to maximize welfare without losses of privacy and unjust reaping of undisclosed workers.

In the digital age, capitalism has been built into free-social-media cyber culture. The forces of production on social media create a sociotechnical apparatus open to change under the dynamics of capitalism. Yet with economics being primarily focused on prices in markets, the 
social process of exchange of information has been left with little attention as being perceived as a naturally given fact.

Future studies should draw attention to these implicit dependency commercial relations and how they shape the sphere of personal time use and consumption as well as societal standing. The laws of motion of information are believed to differ from the laws of requirements of capital accumulation, yet have to be studied further to fully explain. To date, no economic model exists that captures the implicit utility of voluntary information share for the sake of engaging on social media. The use value in such differs from the standard neoclassical notion of utility as not subjectively determined by the buyer of a good. In addition, the consumer of social media is not aware of having become a worker in an implicit contract of joy derived from the interaction on the social media tool and sacrificing his or her productive labor time on the social media virtual market space. The changed social media hierarchy demands for a resolution in studying these entirely new modes of production. Social media identities differing from our real identities or anonymous social media use are proposed alternatives. In this novel insight we need to start estimating the value utility function of the nudged to release information to nudgers and relate it to the economic surplus the nudgers can reap from putting information together and market it to governance professionals.

In the next step, the quantitative relationship between labor hours worked and the real prices charged for information should be expressed in probabilistic terms. In order to transform the value of information sharing into a price of a commodity, research needs to unravel the process whereby people give up some of their privacy for the sake of information sharing and how the products move into markets and are shared with nudgitalists. All these insights will aid to measure a hypothetical price according to pre-existing product-values, which are socially established prior to exchange. The transformation of commodity values into prices of production within nudgitalism and the creation of the surplus value or gross profit component of information are future research areas. Currently we lack understanding how an output is produced, what utility is derived from social media that leads consumer-workers to give up privacy and how exactly value is realized upon data amalgamation and sale in markets to nudgitalists. Social media advancement may be strongly affected by the sales income that social media producers get from selling data.

In the next research steps, a stringent hypotheses testing of the presented problem is recommended. A multi-faceted research plan to study the presented social deficiencies in a well-informed behavioral as well as heterodox way is advised. In such an approach, the article provides the first heterodox analysis of behavioral economics in the public sector. Future research therefore aims at gaining an understanding of behavioral approaches to decision making and develop critical analytical insights to spearhead behavioral economics applied in the public sector domain. An introduction to the classic but also heterodox behavioral economics literature will aid gaining a basic understanding but also critical reflection of contemporary behavioral insights attempts to tackle the most pressing societal concerns.

Future research projects featuring a multi-methodological approach will help gain invaluable information about the interaction of economic market with the real-world economy with direct implications for policy makers alongside advancing an upcoming scientific field. Following empirical investigations should employ a critical survey of the intersection of analytic and behavioral perspectives to decision making in the public sector. Literature discussion featuring a critical analysis how to improve the behavioral economics approach to tackle critical public sector challenges should be coupled with research training and enhancement of 
scientific skills. Research should be directed towards a critical analysis of the application of behavioral economics on public concerns. In the behavioral economics domain, both approaches, studying the negative implications of imperfect behavior on judgment and decision making of public servants but also finding ways how to train public servants making wiser decisions in leading citizens making pro-social decisions should be explored. Interdisciplinary viewpoints and multi-method research approaches should be covered in the heterodox economics readings but also in a variety of independent individual research projects. Research support and guidance should be targeted at nurturing interdisciplinary research interests in the fields of behavioral economics and public affairs.

More concretely, future studies should define the value that data has to individuals and data sovereignty in the international context. When people share information, they should be informed to consider what the benefit and value from sharing is for them and what the benefit for social media industrialists-capitalists is. The sovereignty of data and the human dignity of privacy should become debated as virtual virtue in the $21^{\text {st }}$ century. Individuals should be informed that sharing data is a personal security risk, if considered to be asked for social media information upon entry of a country.

Future studies should describe what companies and institutions constitute the complex system help establishing the nudgital society and the influence that social media has. Politicians may use various channels and instruments to manipulate the populace with targeted communication. The implicit underlying social structure of the nudgital society based on a complicated information gathering machinery should become subject to scrutiny and how, in particular, the nudgital class division is supported by a comprehensive social network data processing method. How social media advertising space can be used to specialize on targeted propaganda and misleading information to nudge the populace in an unfavorable way should be unraveled.

In the recent US election the profit and value of detailed market information has been found to have gained unprecedented impetus. Future research should also draw a line between the results of the 2016 US presidential election, and the study of heuristics to elucidate that heuristics played a key role in Trump's election as they made people less likely to vote logically. This would be key as it would help explain how people chose to vote, and why they do not always make the most logical choice when voting. This line of research could help to more accurately promote future elections' candidates, how to better predict election outcomes and how to improve democracy (Channel, 2017).

In addition, nudging through means of visual merchandising, marketing and advertising should be captured in order to uphold ethical standards in social media. Nudging's role in selling products, maximizing profits but also creating political trends should be uncovered. While there is knowledge on the visual merchandising in stores and window displays, little appears to be known how online appearances can nudge people into making certain choices. In particular, the familiarity heuristic, anchoring and the availability heuristic may play a role in implicitly guide people's choices and discreetly persuade consumers and the populace. Not to mention advancements of online shopping integrity and e-commerce ethics, the prospective insights gained will aid uphold moral standards in economic market places and hopefully improve democratic outcomes of voting choices.

Future research should also investigate how search engines can be manipulated to make favorable sources more relevant and how artificial intelligence and social networks can become dangerous data manipulation means. The role of data processing companies may be 
studied in relation to the idea of data monopoly advantages - hence situations in which data processing companies may utilize data flows for their own purposes to support sponsored causes or their own ideals. Due to the specific time period of the digital age not extrapolations to past time periods is possible but the results appear useful in determining future behaviors.

The current research in this area lacks empirical evidence, demanding for further investigations on how nudges can directly impact individual's choices and new media can become a governance manipulation tool. What social instruments are employed on social media and what prospects data processing has in the light of privacy infringement lawsuits should be uncovered. How social media is utilized to create more favorable social personas for political candidates should be explored. How internet online presences allow to gain as much attraction as possible for the presence of political candidates is another question of concern. All these endeavors will help outlining the existence of social media's influence in governance and data processing to aid political campaigning in order to derive inferences about democracy and political ethicality in the digital age. Another area of concern is how selective representations influence the voting population and what institutions and online providers are enabling repetitiveness and selectivity. How gathered individual information is used to parse data to manipulate social internet behavior and subsequent action is another topic to be investigated. Future research goals will include determining what this means for the future political landscape and how internet users should react to political appearances online. Consumer education should target at educating social media users about their rights and responsibilities on how to guard their own and other's privacy.

The department of Social Psychology at Tilburg University is recruiting two PhD students for two projects on the Social Psychology of Big Data. Candidates are welcome to apply for both projects.

\section{*Moral Psychology of Big Data*}

The first is interested in the moral psychology of big data. The last decade has seen a swift rise in the availability of data about our everyday habits, choices, and preferences. This quick rise has outpaced understanding of what uses people find more or less appropriate for the data. Books have been published on the ethics of big data and potential pitfalls (e.g., O'Neil, 2016), but ironically this question hasn't been tackled with data. The goal of this PhD project is to use theories and tools of moral psychology to understand how people think about the moral tradeoffs involved in big data, morally motivated reasoning about the uses of big data, and people's responses when big data goes wrong. The results will give insight into moral reasoning about a typically amoral topic (i.e., data) and provide both users and creators of big data methods the information necessary to deploy big data in way that does not violate the ethical sensibilities of the public. This project will be supervised by Dr. Mark Brandt, Dr. Christoph Kogler, and Professor Ilja van Beest. A more detailed project description is available upon request from Dr. Mark Brandt (m.j.brandt@tilburguniversity.edu).

\section{*Social Consequences of Big Data Analytics*}

The second is interested in how people think about predictive models based on big data analytics. Models based on big data analytics have had far-reaching effects on public policy. Governments use predictive models to allocate scarce resources and inform policy decisions (Hemerly, 2013), and organizations use them in employment and promotion decisions. Big data models make good predictions, on average, but they may also systematically disadvantage specific subpopulations (O'Neil, 2016). These concerns raise questions about how organizations and policy-makers will implement big data analytics, and how the public will 
react to decisions based on these models. The proposed project will investigate the role of human psychology in big data analytics: First, we will investigate when policy makers prefer to rely on big data analytics (versus human judgments). Second, we will consider how people react to negative outcomes based on these data-driven models. Finally, we will ask how policy makers can use nudges to facilitate trust in the use of data-driven models. This project will be supervised by Dr. Tony Evans and Professor Marcel Zeelenberg. A more detailed project description is available upon request from Dr. Tony Evans (a.m.evans@tilburguniversity.edu).

How social media tools nudge people to not give everything at once but put it together in a novel way that it creates surplus, should be analyzed. In small bits and pieces individuals give up their privacy tranche be tranche. Small amounts of time are spent time for time. People, especially young people, may have a miscalibration about the value of information released about them. Based on hyperbolic discounting myopia, they may underestimate the total future consequences of their share of privacy.

Future studies should also look into the relationship between individual's political ideologies and how they use and interact on social media, especially with a focus on the concept of fake news and alternative facts. Where do these trends come from and who is more susceptible to these negative impacts of the digital society? Has social media become a tool to further polarize political camps, is needed to be asked. In addition, innovative means should be found to restore trust in media information and overcome obstacles such as the availability heuristic leading to disproportionate competitive advantages of media controlling parties. Information should be gathered how we choose what media to watch and if political views play a role in media selection and retention. Does distrust in the media further political polarization and partisanship, needs to be clarified.

The preliminary results may be generalized for other user-generated web contents such as blogs, wikis, discussion forums, posts, chats, tweets, podcastings, pins, digital images, videos, audio files, advertisements but also search engine data gathered or electronic devices (e.g., wearable technologies, mobile devices, Internet of Things). Certain features of the nudgital society may also hold for tracking data, including GPS, geolocation data, traffic and other transport sensor data and CCTV images or even satellite and aerial imagery. All preliminary results should be taken into consideration for future studies in different countries to examine other cultural influences and their effects on social class and heuristics.

Promoting governance through algorism offers novel contributions to the broader data science and policy discussion (Roberts, 2010). Future studies should also be concerned with data governance and collection as well as data storage and curation in the access and distribution of online databases and data streams of instant communication. The human decision making and behavior of data sharing in regards to ownership should become subject to scrutiny in psychology. Ownership in the wake of voluntary personal information sharing and data provenance and expiration in the private and public sectors has to be legally justified (Donahue \& Zeckhauser, 2011). In the future, institutional forms and regulatory tools for data governance should be legally clarified. Open, commercial, personal and proprietary sources of information that gets amalgamated for administrative purposes should be studied and their role in shaping the democracy. In the future we also need a clearer understanding of the human interaction with data and their social networks and clustering for communication results. The guarantee of safety of the information and the guarantee of the replacement or service, should a social media fail its function to uphold privacy law as intended, is another area of blatant future research demand. Novel qualitative and quantitative mixed methods featuring secondary data analysis, web mining and predictive models should be tested for 
holding for the outlined features of the new economy alongside advancing randomized controlled trials, sentiment analysis and smart contract technologies. Ethical considerations of machine learning and biologically inspired models should be considered in theory and practice. Mobile applications of user communities should be scrutinized.

As for consumer-worker conditions, unionization of the social media workers could help uphold legal rights and ethical imperatives of privacy, security and personal data protection. Data and algorithms should be studied by legal experts on licensing and ownership in the use of personal and proprietary data. Transparency, accountability and participation in data processing should also become freed from social discrimination. Fairness-awareness programs in data mining and machine learning coupled with privacy-enhancing technologies should be introduced in security studies of the public sector. Public rights of free speech online in the dialogue based on trust should be emphasized in future educational programs. Policy implications of the presented ideas range from security to human rights and law to civic empowerment. Citizen empowerment should feature community efforts to protect data and information sharing to be free of ethical downfalls. Social media use education should be ingrained in standard curricula and children should be raised with an honest awareness of their act of engagement on social media in the nudgital society of the digital century

\section{References}

Akerlof, G. A. (2009). Animal spirits: How human psychology drives the economy, and why it matters for global capitalism. Princeton, NJ: Princeton University Press.

Bazerman, M. H. \& Tenbrunsel, A. E. (2011). Blind spots: Why we fail to do what's right and what to do about it. Princeton: Princeton University Press.

Bowles, S., Edwards, R. \& Roosevelt, F. (2005). Understanding capitalism: Competition, command, and change. Oxford: Oxford University Press.

Camerer, C. \& Loewenstein, G. (2004). Advances in behavioral economics. New York: Russell Sage.

Camerer, C., Issacharoff, S., Loewenstein, G., O’Donoghue, T. \& Rabin, M. (2003). Regulation for conservatives:

Behavioral economics and the case for „Asymmetric Paternalism“. University of Pennsylvania Law Review, 151, 3, 1211-1254.

Cartwright, E. (2011). Behavioral economics. London: Routledge.

Centeno, M. A., Nag, M., Patterson, T. S., Shaver, A. \& Windawi, J. A. (2015). The emergence of global systemic risk. Annual Review of Sociology, 41, 1-21.

Channel, J. (2017). The Trump effect: Heuristics and electability. Unpublished working paper. The New School: Eugene Lang College and Department of Economics.

deRooij, E. A., Green, D. P. \& Gerber, A. S. (2009). Field experiments on political behavior and collective action. Annual Review of Political Science, 12, 389-395.

Donahue, J. D. \& Zeckhauser, R. J. (2011). Collaborative governance: Private roles for public goals in turbulent times. Princeton: Princeton University Press.Camerer, C. \& Loewenstein, G. (2004). Advances in behavioral economics. New York: Russell Sage.

Evans, A. M. \& Krueger, J. I. (2009). The psychology and economics of trust. Social and Personality Psychology Compass, 3, 6, 1003-1017.

Gigerenzer, G. (2014). Risk savvy: How to make good decisions. Chapter 1: Are people stupid?. New York: Viking. Gigerenzer, G. (2016). Towards a rational theory of heuristics. In R. Frantz \& L. Marsh (Eds.), Minds, models and milieux: Commemorating the centennial of the birth of Herbert Simon. Basingstoke, UK: Palgrave Macmillan.

Heilbroner, R. (1988). Behind the veil of economics: Essays in the worldly philosophy. New York: Norton.

Heilbroner, R. (1999). The worldly philosopher. Chapter 8: The savage society of Thorstein Veblen. New York: Simon \& Schuster. 
Horberg, E. J., Oveis, C., \& Keltner, D. (2011). Emotions as moral amplifiers: An appraisal tendency approach to the influences of distinct emotions upon moral judgments. Emotion Review, 3, 237-244.

Kahneman, D. (2003). Maps of bounded rationality: Psychology of behavioral economics. American Economic Review, 93, 5, 1449-1475.

Kahneman, D. (2011). Thinking, fast and slow. New York: Penguin Book.

Kahneman, D. \& Tversky, A. (1979). Prospect theory: An analysis of decision under risk. Econometrica, 47, 2, 263291.

Kahneman, D. \& Thaler, R. (1991). Economic analysis and the psychology of utility: Applications to compensation policy. American Economic Review, 81, 341-346.

Kahneman, D. \& Tversky, A. (2000). Choices, values, and frames. Cambridge, MA: Cambridge University Press.

Kurz, H.D. (2016). Zur Politischen Ökonomie des homo mercans: Adam Smith über Märkte. In: Hans-Christoph Schmidt am Busch, Die Philosophie des Marktes: The Philosophy of the Market, pp. 23-48. Hamburg: Felix Meiner.

Lerner, J. S., Small, D. A. \& Loewenstein, G. (2004). Heart strings and purse strings: Carryover effects of emotions on economic transactions. Psychological Science, 15, 5, 337-341.

Marglin, S. (1974). What do bosses do? The origins and functions of hierarchy in capitalist production. Review of Radical Political Economics, 6, 60-112.

Marx, K. (1867/1995). Capital: A critique of political economy. Moscow: Progress.

Minsky, H. P. (1977). Banking and a fragile financial environment. The Journal of Portfolio Management, 3, 4, 1622.

Moscovici, S. (1988). Notes towards a description of social representations. Journal of European Social Psychology, $18,3,211-250$.

Paluck, E. L. (2009). What's in a norm? Sources and processes of norm change. Journal of Personality and Social Psychology, 96, 594-600.

Puaschunder, J.M. (2010). On corporate and financial social responsibility. Unpublished Doctoral Thesis. University of Vienna, Faculty of Psychology.

Puaschunder, J. M. (2015). On the social representations of intergenerational equity. Oxford Journal of Finance and Risk Perspectives, 4, 4, 78-99.

Puaschunder, J. M. (2016a). Socially Responsible Investment as emergent risk prevention and means to imbue trust in the post-2008/2009 world financial crisis economy. In: O. Lehner (Ed.), Routledge Handbook of Social and Sustainable Finance, pp. 222-238, London: Taylor \& Francis.

Puaschunder, J. M. (2016b). Trust and reciprocity drive social common goods allocation norms. Proceedings of the Cambridge Business and Economics Conference 2015; Academy of Management Annual Meeting Proceedings.

Roberts, A. S. (2010). The logic of discipline: Global capitalism and the architecture of government. New York: Oxford University Press.

Schumpeter, J. A. (1949). Economic theory and entrepreneurial history. Cambridge, MA: Harvard University Press.

Shaikh, A. (2016). Capitalism: Competition, conflict, crises. Oxford: Oxford University Press.

Sidanius, J. \& Pratto, F. (1999). Social dominance: An intergroup theory of social hierarchy and oppression. New York: Cambridge University Press.

Sen, A. (1977). Rational fools: A critique of the behavioral foundations of economic theory. Philosophy and Public Affairs, 6, 4, 317-344.

Simon, H. A. \& Bartel, R. D. (1986). The failure of armchair economics. Challenge, 29, 5, 18-25.

Tajfel, H. \& Turner, J. C. (1979). An integrative theory of intergroup conflict. In W. G. Austin \& S. Worchel (Eds.), The Social Psychology of Intergroup Relations. Monterey, CA: Brooks-Cole.

Thaler, R. H. \& Sunstein, C. R. (2008). Nudge. Improving decisions about health, wealth, and happiness. New Haven: Yale University Press.

Tversky, A. \& Kahneman, D. (1974). Judgment under uncertainty: Heuristics and biases. Science, 185, 4157, 11241131.

Wagner W. \& Hayes, N. (2005). Everyday discourse and common-sense: The theory of social representation. New 
York: Palgrave Macmillan.

Wagner W., Lorenzi-Cioldi, F., Mankova, I. \& Rose, D. (1999). Theory and method of social representations. Asian Journal of Social Psychology, 2, 1, 95-125.

World Development Report (2015). Mind, society and behavior. Chapter 1 Overview: Human decision making and development policy. 